\title{
Genomic and expression analysis of a solute carrier protein (CCSLC25a5) gene from Cyprinus carpio Linnaeus
}

\author{
Li Jiang ${ }^{*^{*}+}$, Anda Cheng ${ }^{1,2+}$, Yangyang Wang ${ }^{1,3}$ and Baoyong Zhang ${ }^{1,3}$
}

\begin{abstract}
Using the Genefishing method, we identified seven potential regulatory genes involved in the process of scale morphogenesis in fishes. We further characterized a novel solute carrier protein gene (CcSLC), from the common carp which is differentially expressed in mirror carp and Jianli. The ORF encodes a peptide of 298 amino acids with a molecular mass of $31.5 \mathrm{kDa}$ and a theoretical isoelectric point of 7.49 . ScanProsite analysis indicated that it is a putative solute carrier protein that contains a substrate binding site. CCSLC was detected in carp embryos by in situ hybridization in the 70\%-epiboly, 6-somite, and 14-somite embryonic stages. Gene expression stopped at the long pec stage. However, CcSLC25a5 was re-expressed during the initiation of scale formation in the regions that were scale covered. These findings provide novel insights into the features of early carp embryo and scale development.
\end{abstract}

Keywords: Cyprinus carpio Linnaeus; Scale development; Solute carrier protein; Scale initiation; Embryo development

\section{Introduction}

Membrane transporters are the gatekeepers for all cells and organelles, controlling uptake and efflux of crucial compounds such as sugars, nucleotides, inorganic ions, and drugs (Hediger et al. 2004). They are responsible for substrate movement across both cytoplasmic membranes of cells and internal membranes of organelles (Sreedharan et al. 2011). Transporters can be divided into $\mathrm{ABC}$ transporters, pumps, ion channels, water channels, and solute carriers. Membrane bound proteins represent about $27 \%$ of the entire human proteome. Among the membrane bound proteins, the SLC transporters are the second largest group after $G$ protein coupled receptors (Lagerstrom 2008, Almen et al. 2009). Transporters can be divided into two families, passive and active transporters. The active transporters use diverse energy-coupling mechanisms to allow the movement of molecules across a membrane against a concentration gradient. The passive transporters, also known as

\footnotetext{
*Correspondence: jiangl@cafs.ac.cn

${ }^{\dagger}$ Equal contributors

${ }^{1}$ The Center for Applied Aquatic Genomics, Chinese Academy of Fishery Sciences, Beijing 100141, China

Full list of author information is available at the end of the article
}

facilitated transporters, allow passage of solutes (e.g., glucose, amino acids, urea) across membranes down their electrochemical gradients (Hediger et al. 2004).

Appreciation of the role that transport proteins play in the absorption, distribution, and elimination of a wide variety of drugs in clinical use is increasing. As the largest group of secondary transporters, SLC transporters are becoming the focus of an increasing number of studies because they control transmembrane movement of many types of important substrates. The human genome contains approximately 360 unique SLC protein genes grouped into 48 families (Ren et al. 2007; Fredriksson et al. 2008). Approximately 19 of the SLC gene families have been reported to transport xenobiotics including: organic anion polypeptides (SLCO), oligopeptides (SLC15) (Russel et al. 2002; Brandsch et al. 2008; Dobson and Kell 2008; Rubio and Daniel 2008), organic anion/cations (SLC22) (Koepsell et al. 2007; Ciariboli 2008), and organic cations (SLC47) (Tanihara et al. 2007; Moriyama et al. 2008; Matsushima et al. 2009).

The $S L C 25$ gene encodes mitochondrial carriers (MCs), which are membrane-integrated proteins that localize to the inner membranes of mitochondria and catalyze the translocation of solutes across the membranes (Plamieri, 
2004). The MCs provide a critical link between the mitochondria and the cytosol by facilitating the flux of solutes through the permeable barrier of the inner mitochondrial membrane. The substrates transported by the MCs range from the smallest $\mathrm{H}+$ to the largest ATP molecule, implying that they have a broad array of functions in diverse metabolic processes. Defects in MC genes lead to several diseases such as type II citrullinaemia (SLC25A13; OMIM 215700), hyperornithine-hyperammone- homocitrullinemia (HHH) syndrome (SLC25A15; OMIM 238970), Stanley syndrome (SLC25A20; OMIM 212138), Amish microcephaly (SLC25A20; OMIM 607196), and autosomal dominant progressive external ophthalmoplegia (adPEO) (SLC25A4; OMIM 157640). The complete amino acid sequence of the ATP/ADP carrier was identified in beef heart mitochondria (Aquila et al. 1982; Aquila et al. 1985).

Post-genomic era studies have enabled us to identify many more mitochondria carrier families (MCFs) simultaneously without laborious cloning or purification procedures. Although much is known about the characteristics and functions of MCFs in human and plants, their biological roles in fish remain unknown. In our studies, we cloned the CcSLC25a5 (Cyprinus Carpio SLC25a5) gene using Genefishing kits from the skins of the mirror carp, which has interspersed scales, and the Jianli, that has full scales. The expression pattern of SLC25a5 during different developmental stages was determined by whole-mount in situ hybridization.

\section{Materials and methods}

Animals

Mirror carp and Jianli (Cyprinus carpio Linnaeus) were cultivated at Experimental Station of the Wuxi Freshwater Center, Jiangsu, China. The mirror carp was derived by domesticating the common carp and selecting for a scale-reduced mutation fgfrla (Rohner et al. 2009). The skin tissues from mirror carp and Jianli were harvested with forceps and immediately homogenized in $1 \mathrm{ml}$ Trizol (Invitrogen).

\section{First-strand CDNA synthesis}

Total RNA extracted from the skin tissues using Trizol reagent (Invitrogen) was used to synthesis the first-strand cDNA. Subsequent reverse transcription was performed according to the manufacture's protocol (Seegene, Seoul, South Korea). The final reaction volume was $20 \mathrm{uL}$ and contained: 3 ug of purified total RNA, $4 \mathrm{uL}$ of $5 \times$ reaction buffer, $5 \mathrm{uL}$ of dNTPs ( $2 \mathrm{mM}$ each), $2 \mathrm{uL}$ of $10 \mathrm{uM} \mathrm{dT}$ ACP1 (5' -GTCTACCAGGCATTCGCTTCATXXXXXGC CATCGACC-3'), 0.5 uL RNase inhibitor (40 U/uL; Invitrogen, USA), and $1 \mathrm{uL}$ of reverse transcriptase $(200 \mathrm{U} / \mathrm{uL}$, Invitrogen). First-strand cDNAs were diluted using $80 \mathrm{uL}$ of DNase-free water for GenefishingTM PCR, and stored at $-20^{\circ} \mathrm{C}$.

\section{ACP (Annealing Control Primer)-based Genefishing PCR} DEGs (Differential Expressed Genes) were screened by ACP-based PCR methodology using the Genefishing DEG Kits (Seegene). Briefly, second-strand cDNA was synthesized at $50^{\circ} \mathrm{C}$ during in the first-stage PCR reaction. The final reaction was conducted in a $20 \mathrm{uL}$ volume containing: $3-5 \mathrm{uL}$ of diluted first-strand cDNA, 1 $\mathrm{uL}$ of dT-ACP2 (10 uM), 1 uL of $10 \mathrm{uM}$ arbitrary ACP (Hwang et al. 2005), and $10 \mathrm{uL}$ of $2 \times$ Master Mix (Seegene). The PCR protocol for second-strand synthesis was: one cycle at $94^{\circ} \mathrm{C}$ for 5 minutes, followed by $50^{\circ} \mathrm{C}$ for 3 minutes, and $72^{\circ} \mathrm{C}$ for 1 minute. Once the secondstrand DNA synthesis was completed, a second-stage PCR amplification protocol was conducted that consisted of: 40 cycles of $94^{\circ} \mathrm{C}$ for 40 seconds, $65^{\circ} \mathrm{C}$ for 40 seconds, and a 5 minute final extension at $72^{\circ} \mathrm{C}$. The amplified PCR products were separated in a $2 \%$ agarose gel and stained with ethidium bromide.

\section{Cloning and sequencing}

PCR bands indicating genes with differential expression were extracted from the gel using a DNA extraction kit (Zomanbio, China). The bands were directly cloned into a pEASY-T vector (Trans, China) according to the manufacturer's instructions. The cloned plasmids were sequenced.

\section{Whole-mount in situ hybridization}

RNA probes were prepared from a 206 bp CDS (Coding Sequence) region of the gene SLC25a5 in common carp and labeled with digoxigenin-UTP using T3 or T7 RNA polymerase ( $\mathrm{T} 3$ for production of the antisense probe, T7 for the sense probe). The embryonic and developmental stages of the embryos used for whole-mount in situ hybridization were assessed using haf (hours after fertilization) and various morphological criteria (Kane and Kimmel 1993) as described by Westerfield (1993). The RNA probes were hybridized to the tissue overnight at $65^{\circ} \mathrm{C}$. The embryos and juvenile fish from each developmental stage were imaged using an Olympus BH-2 microscope (Olympus Optical, Tokyo, Japan). The primers used to create the probes were: Forward: $5^{\prime}$-TGGG TAACTGCTTGGTGAAGATCTCC-3', and Reverse: 5' -A CCAGCAACAGCAGTCACAGTCTGA-3'.

\section{Results}

The mirror carp and Jianli have differential gene expression in skin tissues

To identify the differentially expressed genes that are associated with development of the skin and appendages, skin samples from mirror carp and Jianli were assayed by Genefishing. The Genefishing assay used an anchored primer in combination with 20 arbitrary primers (Arbitrary ACP, Annealing Control Primer) (Table 1). We obtained 
seven DEGs from all ACP primers (Table 2), among these DEGs, two PCR products from ACP28 and ACP29 primers were identified that had significantly different expression levels (Figure 1). The differentially expressed bands were subcloned into pEasy-T3 vector and sequenced. The sequences were compared using the blast program in the NCBI sequence database (http://wei.sohu.com/20121011/ n354628269.shtml). The blast results showed that the differentially expressed genes identified using the primers ACP28 and ACP29 were homologues of the zebrafish SLC25a5 (Solute carrier) and TPT1 (Tumor protein, translationaly-controlled1) genes, respectively. We have named them CcSLC25a5 (The Common carp SLC25a5) and CCTPT1 (The Common carp TPT1).

\section{CCSLC25a5 gene structure and its isoforms}

One of the identified genes, CcSLC25a5, was selected for further analysis. We designed the primers located in the conserved region of the gene using the partial reference sequence of CcSLC25a5 isoform 1. Nine different isoforms of the CcSLC25a5 gene were identified in the common carp and Jianli. The genes encode six different SLC25a5 protein isoforms due to codon degeneracy. Four isoforms were found in the common carp and two isoforms were

Table 1 Primers used in genefishing for amplifying the differential expressed genes in skin of jianli and mirror carp

\begin{tabular}{|c|c|}
\hline Primers & Primer sequence \\
\hline ACP1 & GTCTACCAGGCATTCGCTTCATXXXXXGCCATCGACC \\
\hline ACP2 & GTCTACCAGGCATTCGCTTCATXXXXXAGGCGATGCC \\
\hline ACP3 & GTCTACCAGGCATTCGCTTCATXXXXXCCGGAGGATG \\
\hline ACP4 & GTCTACCAGGCATTCGCTTCATXXXXXGCTGCTCGCG \\
\hline ACP5 & GTCTACCAGGCATTCGCTTCATXXXXXAGTGCGCTCG \\
\hline ACP6 & GTCTACCAGGCATTCGCTTCATXXXXXGGCCACATCG \\
\hline ACP7 & GTCTACCAGGCATTCGCTTCATXXXXXCTGCGGATCG \\
\hline ACP8 & GTCTACCAGGCATTCGCTTCATXXXXXGGTCACGGAG \\
\hline AC P9 & GTCTACCAGGCATTCGCTTCATXXXXXGATGCCGCTG \\
\hline ACP10 & GTCTACCAGGCATTCGCTTCATXXXXXTGGTCGTGCC \\
\hline ACP11 & GTCTACCAGGCATTCGCTTCATXXXXXCTGCAGGACC \\
\hline ACP12 & GTCTACCAGGCATTCGCTTCATXXXXXACCGTGGACG \\
\hline ACP13 & GTCTACCAGGCATTCGCTTCATXXXXXGCTTCACCGC \\
\hline ACP14 & GTCTACCAGGCATTCGCTTCATXXXXXGCAAGTCGGC \\
\hline ACP15 & GTCTACCAGGCATTCGCTTCATXXXXXCCACCGTGTG \\
\hline ACP16 & GTCTACCAGGCATTCGCTTCATXXXXXGTCGACGGTG \\
\hline ACP17 & GTCTACCAGGCATTCGCTTCATXXXXXCAAGCCCACG \\
\hline ACPI18 & GTCTACCAGGCATTCGCTTCATXXXXXCGGAGCATCC \\
\hline ACP19 & GTCTACCAGGCATTCGCTTCATXXXXXCTCTGCGAGC \\
\hline$A C P 2 D$ & GTCTACCAGGCATTCGCTTCATXXXXXGACGTTGGCG \\
\hline
\end{tabular}

Table 2 Seven candidate GOIS (gene of interest) by genefishing

\begin{tabular}{cc}
\hline GOI number & Protein \\
\hline 1 & Solute carrier family 25 alpha, member 5 (slc25a5) \\
2 & Hairless protein \\
3 & Cyprinus carpio translationally-controlled \\
& tumor protein mRNA, complete cds \\
4 & Danio rerio myosin heavy chain, fast skeletal \\
& muscle-like, 85 bp (89\%) \\
5 & Actin, alpha, cardiac muscle 1 b [Danio rerio], \\
6 & $367 / 389(94 \%)$ \\
7 & Dictyostelium discoideum AX4 hypothetical protein, \\
& $84 / 87$ (97\%) \\
\hline
\end{tabular}

found in the mirror carp (Figure 2). The full-length CCSLC cDNA consists of 1697 nucleotides with an 897 base pair open reading frame (ORF). The ORF encodes a peptide of 298 amino acids with a molecular mass of $31.5 \mathrm{kDa}$ and a theoretical isoelectric point of 7.49. There are seven amino acid positions that are different between the isoforms (Figure 2). SLC25a5 has six putative transmembrane domains, which are composed of three repeats of mitochondrial carrier protein features by searching the Pfam database (Finn et al. 2010). SLC25a5 also contains one substrate binding site (Figure 2) and encodes an adenine nucleotide translocator (ANT2). ANT2 (also named as SLC25a5) is the most abundant mitochondrial protein (Itoi et al. 2005).

Using the CCSLC25a5 mRNA sequence as a query, we searched our assembled genome database of Cyprinus carpio (not published), two copies of CCSLC25a5 exist on one scaffold (scaffold ID: 000000476), they are adjacent to each other and have the converse gene directions. By comparing the genomic and transcript sequences, the CcSLC25a5 has four exons and three introns (Figure 3). We then compared the carp gene to known zebrafish and human isoforms. Zebrafish have ANT1 (SLC25a4) and ANT2 (SLC25a5) genes, while humans have three ANT genes: ANT1, ANT2, and ANT3. Similar to the carp, the zebrafish ANT1 and the human ANT1, ANT2, and ANT3 genes contain four exons (Figure 3). The exception is the zebrafish ANT2 gene which contains three exons (Figure 3).

\section{Phylogenetic analysis of cyprinid fishes and mammalian SLC25a5 isoforms}

To analyze the phylogenetic relationship of ANTs in cyprinid fishes, a phylogenetic tree was constructed using neighbor-joining from deduced amino acid sequences (Figure 4). The six carp isoforms were clustered into one branch. They are more closely related to human and bovine ANT3, and more distantly to mammalian 


\section{ACP28 \\ ACP29}

\section{$\mathrm{KL}-2$}

JL-2 DL5000 KL-2 JL-2

Figure 1 Differential gene expression detected in the Genefishing assay using primers ACP28 and ACP29. The PCR products from the genefishing assay were separated by agarose gel electrophoresis. Gene products that are differentially expressed in the mirror carp (KL-2) and common carp (JL-2) are shown by green arrows. DL5000 indicate molecular markers.

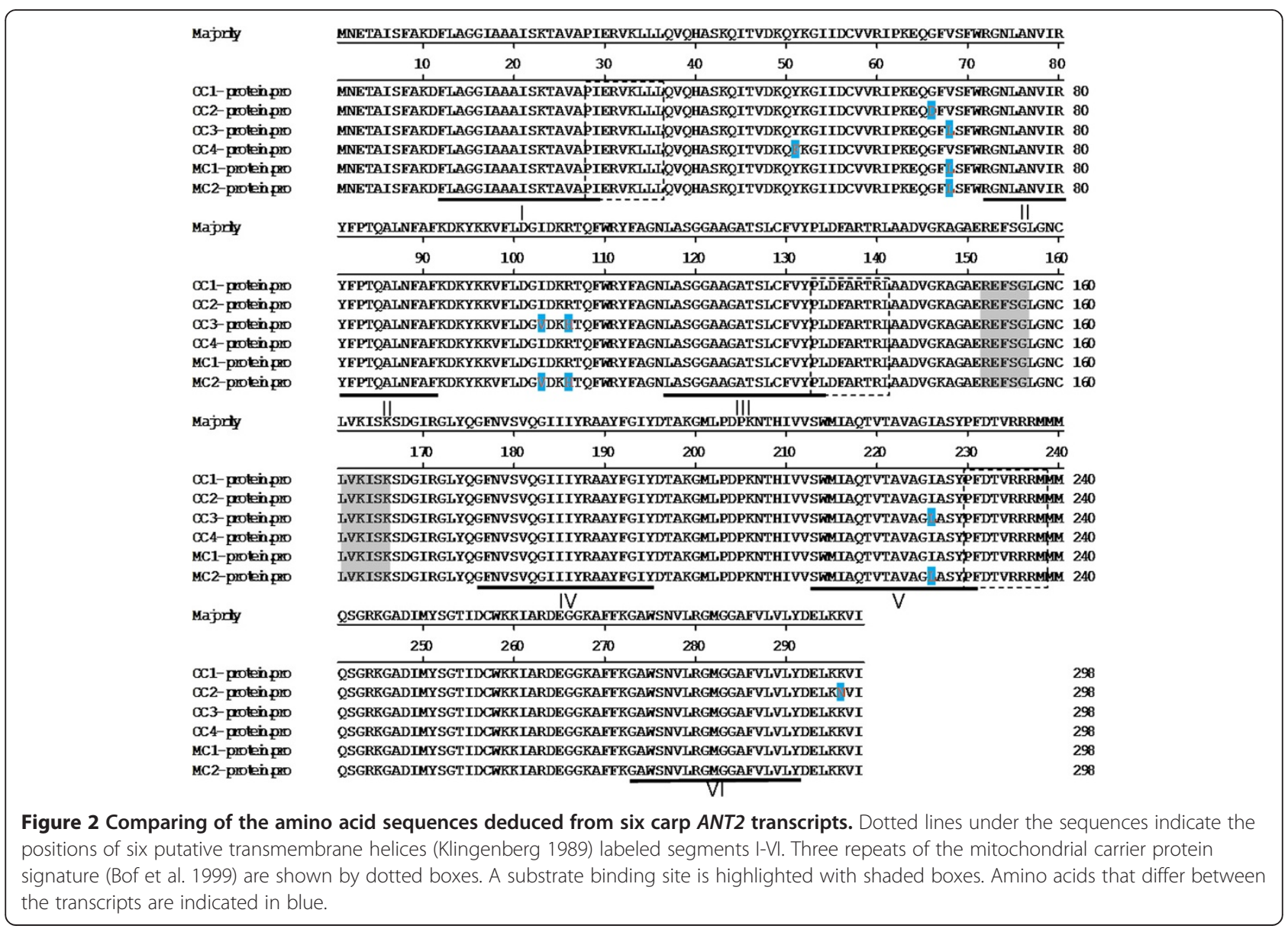




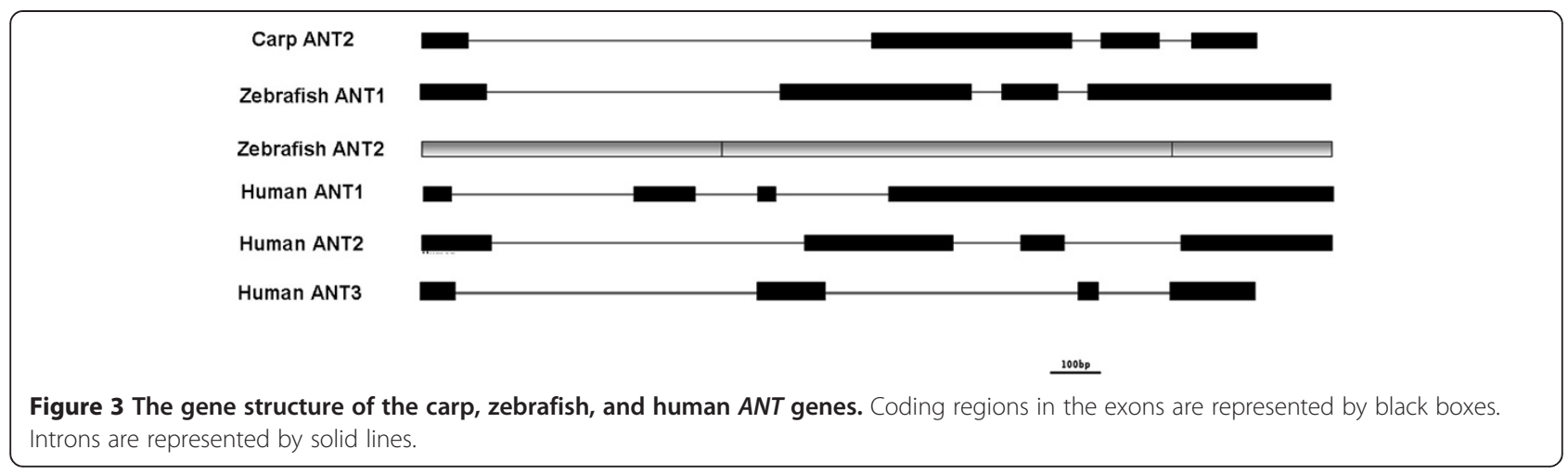

ANT1s (rat, mouse, bovine, human) and ANT2s (mouse, bovine, rat, human). The deduced amino acid sequence of the CcSLC25a5 protein shares a high degree of homology with other known vertebrate SLCs (82\% identity with mouse, bovine, rat, human).

\section{Tissue expression of the CCSLC25a5}

To define the timing and patterns of CcSLC25a5 expression during early embryonic development, we performed in situ hybridization throughout the earlier developmental stages. The SLC25a5 gene was expressed weakly in embryos from 4.5 (1/3 epiboly stage, Figure 5A) to 6 (shield stage, Figure 5B) hpf (hours post fertilization). However, a strong expression signal appeared at the $70 \%$ epiboly stage (10 hpf, Figure $5 \mathrm{C})$. The gene expression signal was concentrated in the embryo and undetectable in the yolk. SLC25a5 was continuously expressed beginning $10 \mathrm{hpf}$ (6-somites stage) to $16 \mathrm{hpf}$ (14-somites stage) (Figure 5D-F) and continuing until 48 hpf (long-pec stage, Figure 5G) when the signal gradually weakened. Interestingly, CcSLC25a 5 was specifically expressed in the scale placods as the scale pattern was formed (Figure $5 \mathrm{H}$ ).

\section{Discussion}

Scales of the teleost fish are important skin integumentary appendages distributed over the body surface in defined patterns. Natural variation in scale patterns exists among the common carp species. Mirror carp and Jianli are two carp varieties that have distinct scale patterns as a result of breeding selection. Scale initiation and morphogenesis are very complicated biological processes. The functional analysis of FGFR 1 by reverse genetics showed that the mutation of this gene can lead to reduced scales and abnormal fins (Rohner et al. 2009). The scale is one of the important agricultural traits for fishes and play important roles in physiology, defense, and adaptation to new environments (Sire et al. 1997). Some aquatic biologists are interested in scale development and launched some works using the reverse genetics. However, a complete knowledge of scale development is limited due to the longer sexual maturation period and the larger genome size for many species in fishes. Therefore, the molecular mechanisms underlying the scale initiation and pattern formation remain unknown. Using Genefishing, we were able to identify seven genes that were differentially expressed in Jianli and mirror carp

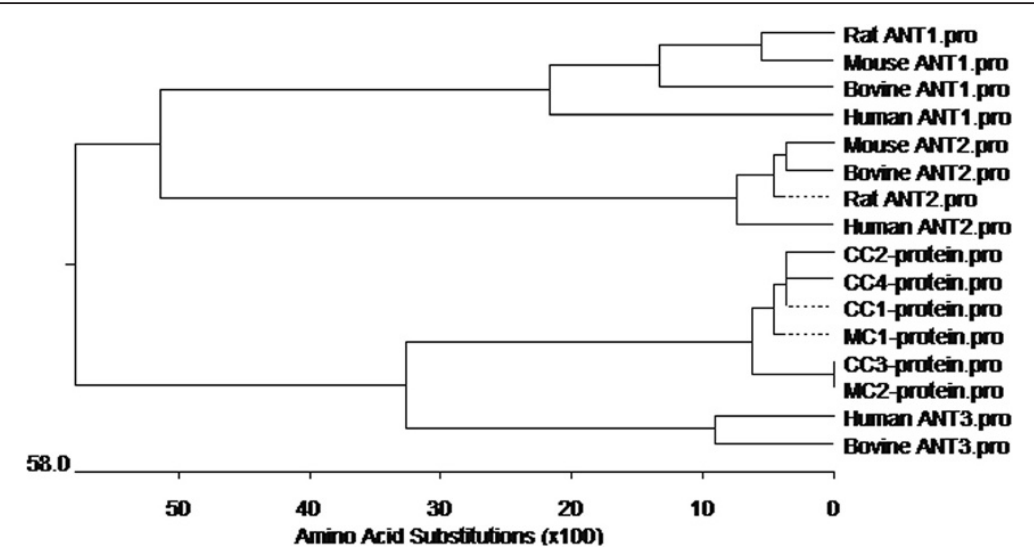

Figure 4 A phylogenetic tree of carp and mammalian ANT isoforms constructed using the neighbor-joining methodology. The evolutionary distance between amino acid substitutions was estimated using Kimura's two parameter-method (Kimura 1980). The scale along the bottom axis shows the evolutionary distance of amino acid substitutions per site. 

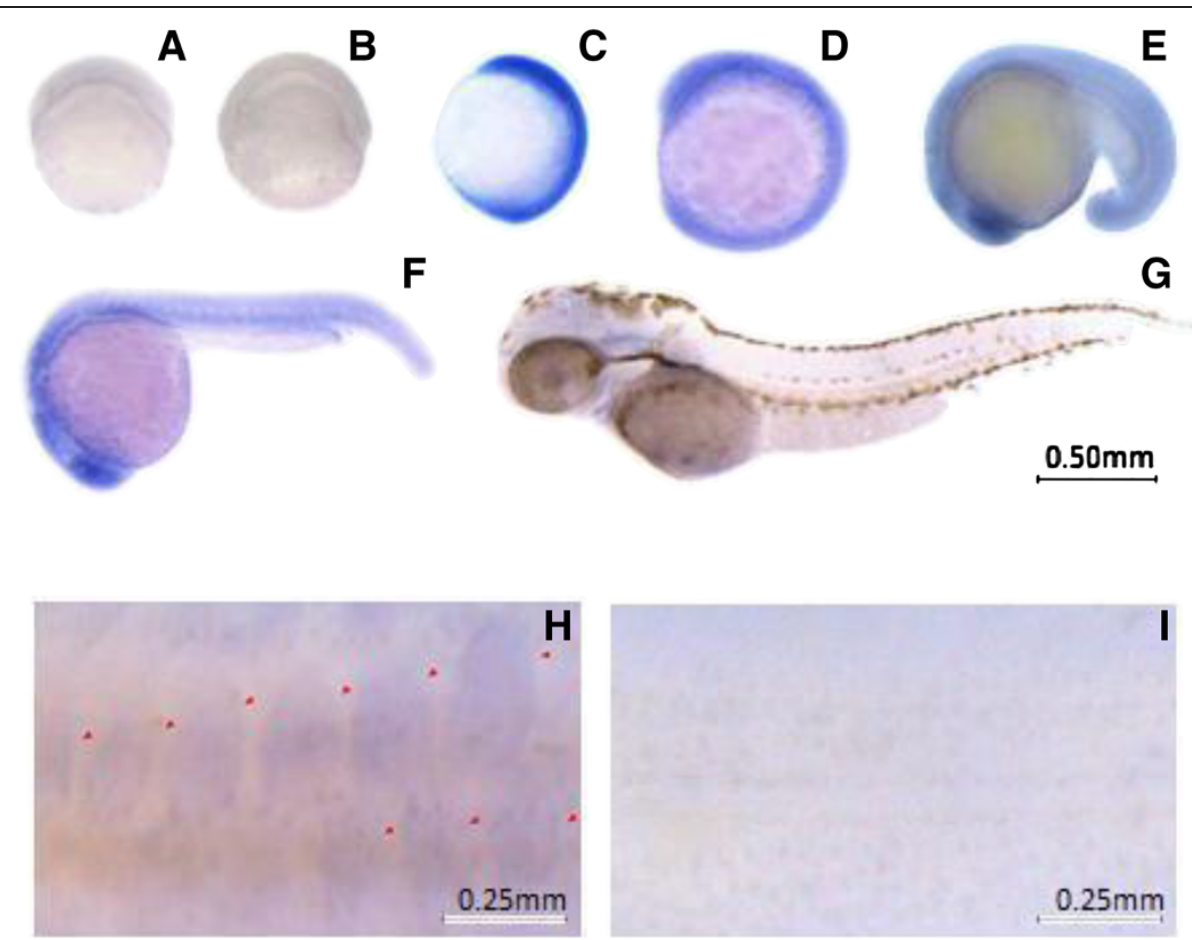

Figure 5 The CCSLC25a5 expression pattern by whole-mount in situ. Panels A-G show the expression pattern of CCSLC25a5 genes in different developmental stages. (A) 4.5 haf (1/3 epiboly), (B) 6 haf (shield), (C) 10 haf, (D) 12 haf, (E) 16 haf, (F) 24 haf, and (G) 48 haf after fertilization, respectively. (H) SLC25a5 is expressed specifically in the regions where the scales were developing in the skin. (I) There is no hybridization signal detected using the sense probe as the negative control.

skin tissues (Table 2). These genes may contribute to the morphogenesis of the integumentary appendages, especially the scales or fins, the functional analysis of these seven genes will be performed in future studies.

ANTs are the most abundant mitochondrial proteins and mediate the exchange of ADP and ATP across the mitochondrial membrane. They link ATP production in mitochondria to its functional utilization for energy requirements outside mitochondria (Klingenberg 1981 and 1989). Humans are known to have three ANT genes. ANT1 is predominantly expressed in the heart and skeletal muscle and $A N T 2$ is expressed in kidney and liver. ANT3 is expressed ubiquitously but is highest in the kidney (Stepien et al. 1992). The tissue distributions of different ANT isoforms seem to reflect their functional differences and associate with tissue-specific energy metabolism (Stepien et al. 1992).

Given their tissue specific roles in humans, it was of interest to examine expression profiles of ANT isoforms in various tissues in the carp. To date, there are no reports about $A N T$ expression in fish scales. Herein, we report that ANT2 is specifically expressed in the scale placods. This result indicates that ANT2 may have an important role in scale development and morphogenesis. It has been suggested that fish ANTs have an important role in energy production, which is associated with temperature adaptation in fish. Guderley and Johnston (1996) reported that the uptake of ADP in isolated mitochondria from cold-acclimated sculpin was higher than that of their warm-acclimated counterparts. CCSLC25a5 possibly involved in the energy production in scale development for fishes, so it should be expressed in the process of scale development. Additional studies will provide new insights into the regulation of energy metabolism during scale development in fish.

We next examined the expression profiles of CcSLC25a5 in various tissues of the Jianli during development. CcSLC25a5 was weakly expressed in early stages of embryo development (4.5 to 6 hpf, Figure 5A-B). However, strong expression signals were detected in embryos from 10 to $24 \mathrm{hpf}$ (Figure 5C-F). These results imply that CCSLC25a5 has roles in embryo and scale development.

\section{Competing interest}

The authors declare that no competing interests exist.

\section{Authors' contributions}

$\mathrm{L}$ designed the project, carried out research and made the drafted manuscript. ADC carried out most of the experiments, YYW revised the manuscript, BYZ did data collection. All authors read and approved the final manuscript.

\section{Acknowledgements}

This study was supported by the grants from the Research Foundation of the Chinese Academy of Fishery Sciences (No. 2011C015, No. 2010C017, No 
2012C015), the China Ministry of Agriculture 948 Program (2011-G12), and the China Ministry of Science and Technology $863 \mathrm{Hi}$-Tech Research and Development Program (No.2011AA100401)

\section{Author details}

${ }^{1}$ The Center for Applied Aquatic Genomics, Chinese Academy of Fishery Sciences, Beijing 100141, China. ${ }^{2}$ College of Fisheries and Life Science, Shanghai Ocean University, Shanghai 201306, China. ${ }^{3}$ College of Fisheries and Life Science, Dalian Ocean University, Dalian 116023, China.

Received: 22 May 2013 Accepted: 4 September 2013

Published: 12 September 2013

\section{References}

Almen MS, Nordstrom KJ, Fredriksson R, Schioth HB (2009) Mapping the human membrane proteome: a majority of the human membrane proteins can be classified according to function and evolutionary origin. BioMed Central Biology 7:50. doi:10.1186/1741-7007-7-50

Aquila H, Misra D, Eulitz M, Klingenberg M (1982) Complete amino acid sequence of the ADP/ATP carrier from beef heart mitochondria. Hoppe-Seyler's Z Physiol Chem 363:345-349

Aquila H, Link TA, Klingenberg M (1985) The uncoupling protein from brown fat mitochondria is related to the mitochondrial ADP/ATP carrier. Analysis of sequence homologies and of folding of the protein in the membrane. EMBO J 4:2369-2376

Bof M, Brandolin G, Satre M, Klein G (1999) The mitochondrial adenine nucleotide translocator from Dictyostelium discoideum. Functional characterization and DNA sequencing. European Journal of Biochemistry 259:795-800

Brandsch M, Knutter I, Bosse-Doenecke E (2008) Pharmaceutical and pharmacological importance of peptide transporters. J Pharm Pharmacol 60:543-585

Ciariboli G (2008) Organic cation transporters. Xenobiotica 38:936-971

Dobson PD, Kell DB (2008) Carrier-mediated cellular uptake of pharmaceutical drugs: an exception or the rule? Nat Rev Drug Discov 7:205-220

Finn RD, Mistry J, Coggill P, Heger A, Pollington JE, Gavin OL, Gunasekaran P, Ceric G, Forslund K, Holm L, Sonnhammer EL, Eddy SR, Bateman A (2010) The Pfam protein families database. Nucleic Acids Res 38:211-222

Fredriksson R, Nordström KJV, Stephansson O, Hägglund MGA, Schiöth HB (2008) The solute carrier (SLC) complement of the human genome: Phylogenetic classification reveals four major families. FEBS Lett 582:3811-3816

Guderley H, Johnston LA (1996) Plasticity of fish muscle mitochondria with thermal acclimation. J Exp Biol 199:1311-1317

Hediger MA, Michael F, Romero MF, Peng JB, Rolfs A, Takanaka H, Bruford EA (2004) The ABCs of solute carriers: physiological, pathological and therapeutic implications of human membrane transport proteins. Pflügers Archive European Journal of Physiology 447:465-468

Hwang DY, Cho JS, Oh JH, Shim SB, Jee SW, Lee SH, Seo SJ, Lee SK, Lee SH, Kim YK (2005) Differentially Expressed Genes in Transgenic Mice Carrying Human Mutant Presenilin-2 (N141I): Correlation of Selenoprotein M with Alzheimer's Disease. Neurochem Res 30:1009-1019

Itoi S, Misaki R, Hirayama M, Nakaniwa M, Liang CS, Kondo H, Watabe S (2005) Identification of three isofoms for mitochondrial adenine nucleotide translocator in the pufferfish Takifugu rubripes. Mitochondrion 5:162-172

Kane DA, Kimmel CB (1993) The zebrafish midblastula transition. Development 119:447-456

Kimura M (1980) A simple method for estimating evolutionary rates of base substitutions through comparative studies of nucleotide sequences. J Mol Evol 16:111-120

Klingenberg M (1981) Membrane protein oligomeric structure and transport function. Nature 290:449-454

Klingenberg M (1989) Molecular aspects of the adenine nucleotide carrier from mitochondria. Arch Biochem Biophys 270:1-14

Koepsell H, Lips K, Volk C (2007) Polyspecific organic cation transporters: structure, function, physiological roles, and biopharmaceutical implications. Pharm Res 24:1227-1251

Lagerstrom MC, Schioth HB (2008) Structural diversity of G protein-coupled receptors and significance for drug discovery. Nat Rev Drug Discov 7:339-357

Matsushima S, Maeda K, Inoue K, Ohta KY, Yuasa H, Kondo T, Nakayama H, Horita S, Kusuhara H, Sugiyama $Y$ (2009) The inhibition of human multidrug and toxin extrusion 1 is involved in the drug-drug interaction caused by cimetidine. Drug Metabolism Disposition 37:555-559

Moriyama Y, Hiasa M, Matsumoto T, Omote H (2008) Multidrug and toxic compound extrusion (MATE)-type proteins as anchor transporters for the excretion of metabolic waste products and xenobiotics. Xenobiotica 38:1107-1118

Plamieri F (2004) The mitochondrial transporter family (SLC25): physiological and pathological implications. Pflügers Archive European Journal of Physiology 447:689-709

Ren Q, Chen K, Paulsen IT (2007) Transporter DB: A comprehensive database resource for cytoplasmic membrane transport systems and outer membrane channels. Nucleic Acids Res 35:274-279

Rohner N, Bercsényi M, Orbán L, Kolancayk ME, Linke D, Brand M, Nüsslein-Volhard C, Harris MP (2009) Duplication of fgfr 1 Permits Fgf Signaling to Serve as a Target for Selection during Domestication. Curr Biol 19:1642-1647

Rubio Al, Daniel H (2008) Peptide transporters and their roles in physiological processes and drug disposition. Xenobiotica 38:1022-1042

Russel FG, Masereeuw R, Van ARA (2002) Molecular aspects of renal anionic drug transport. Annu Rev Physiol 64:563-594

Sire JY, Allizard F, Babiar O, Bourguignon J, Quilhac A (1997) Scale development in zebrafish (Danio rerio). J Anat 190:545-561

Sreedharan S, Stephansson O, Schiöth HB, Fredriksson R (2011) Long evolutionary conservation and considerable tissue specificity of several atypical solute transporters. Gene 478:11-18

Stepien G, Torroni A, Chung AB, Hodge JA, Wallace DC (1992) Differential expression of adenine nucleotide translocator isoforms in mammalian tissues and during muscle cell differentiation. J Biol Chem 267:14592-14597

Tanihara Y, Masuda S, Sato T, Katsura T, Ogawa O, Inui K (2007) Substrate specificity of MATE1 and MATE2-K human multidrug and toxin extrusions/H (+)-organic cation antiporters. Biochemistry Pharmacology 74:359-371

Westerfield M (1993) The zebrafish book: a guide for the laboratory use of zebrafish (Brachydanio rerio). M. Westerfield, Eugene, OR

doi:10.1186/2193-1801-2-458

Cite this article as: Jiang et al:: Genomic and expression analysis of a solute carrier protein (CCSLC25a5) gene from Cyprinus carpio Linnaeus. SpringerPlus 2013 2:458.

\section{Submit your manuscript to a SpringerOpen ${ }^{\circ}$ journal and benefit from:}

- Convenient online submission

$\checkmark$ Rigorous peer review

- Immediate publication on acceptance

- Open access: articles freely available online

- High visibility within the field

- Retaining the copyright to your article

Submit your next manuscript at $>$ springeropen.com 